\title{
SAÚDE DO TRABALHADOR NO ÂMBITO MUNICIPAL
}

\author{
Zilda Pereira da Silva \\ Irineu Francisco Barreto Junior \\ Maria do Carmo Sant’Ana
}

\begin{abstract}
Resumo: O novo padrão mundial de produção e comércio tem produzido mudanças no mundo do trabalho, nos determinantes da saúde-doença e na organização das práticas de saúde e de segurança no trabalho. No Brasil, transformações importantes vêm ocorrendo com o processo de descentralização das ações e dos serviços de saúde. A Pesquisa Municipal Unificada, da Fundação SEADE, identificou que, em 1999, 26\% das prefeituras paulistas realizavam ações de saúde do trabalhador, mais freqüentemente em municípios maiores e em Gestão Plena do Sistema.

Palavras-chave: saúde do trabalhador; descentralização; informações municipais.

Abstract: The new worldwide standard of production and commerce has produced changes in the workplace with regard to sickness/health and in the organization of occupational safety and health practices. In Brazil, important transformations are occurring as a result of the decentralization of activity and health care services. The Unified Municipal Study, by the SEADE Foundation, revealed that in 1999, 26\% of municipal governments in the State of São Paulo carried out health care-related activities aimed at workers, most frequently in larger cities and through large coordinated efforts.

Key words: employee health; decentralization; municipal information.
\end{abstract}

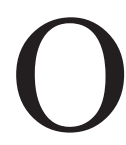
padrão mundial de produção e comércio, caracterizado pelo processo de globalização da economia, de reestruturação produtiva e de reconversão profissional, tem introduzido mudanças radicais na vida e nas relações entre países e pessoas, provocando transformações socioeconômicas/culturais no mundo do trabalho, nos determinantes da saúde-doença, no quadro da morbimortalidade relacionada ao trabalho e na organização das práticas de saúde e de segurança no trabalho.

O processo saúde-doença dos trabalhadores - como e porquê adoecem e morrem - e como são organizadas e atendidas suas necessidades de saúde podem ser considerados uma construção social diferenciada no tempo, lugar e dependente da organização das sociedades (Dias, 2000). Os agravos à saúde dos trabalhadores englobam, além dos acidentes de trabalho, as doenças profissionais - aquelas que apresentam relação nítida com o trabalho, sendo inerentes aos indíviduos que desenvolvem alguma atividade produtiva, que é a causa inequívoca da doença -, e as doenças relacionadas ao trabalho - aquelas em que não existe pressuposto da inerência, sendo o trabalho assumido como co-fator na etiologia da doença (Wünch Filho, 1995).
O Relatório da Organização Internacional do Trabalho - OIT, apresentado na XIV Reunião Regional Americana, realizada em Lima, em agosto de 1999, com o tema Trabalho Decente e Proteção para Todos como Prioridade das Américas, afirma que a globalização dos mercados de capital e a ausência de mecanismos de regulação financeira incrementaram a dependência de economias com relação à dívida externa de curto prazo e os empréstimos de alto risco, o que pressiona países a adotarem políticas de ajuste recessivo, afetando significativamente o mercado de trabalho. Ainda que, durante os anos 90, as economias da América Latina tivessem crescido e reduzido a inflação, isto não significou melhora no campo do trabalho, na situação do emprego e do salário. Este período caracteriza-se por moderada recuperação do crescimento econômico, pela expansão da força de trabalho, pelo aumento do desemprego e à insuficiente geração de postos de trabalho, combinados com a desaceleração do ritmo de crescimento do PIB, a não-recuperação do salário mínimo em termos reais e a evolução do ingresso dos trabalhadores no emprego informal. Nesse quadro econômico, os trabalhadores ligados a indústrias de pequeno porte, os autônomos/temporários ou os do setor informal 
tiveram menos garantia de emprego. O relatório aponta ainda outro fenômeno importante: o aumento da terceirização remete a tarefas insalubres, monótonas e perigosas, cuja pulverização das atividades em diversas unidades dificulta as ações do setor saúde, o que constitui um desafio à proposta de promoção de saúde (OIT, 1999).

A dinâmica social do trabalho está intrinsecamente relacionada ao processo saúde-doença das sociedades humanas. No mundo contemporâneo, a automação e a renovação dos equipamentos - microeletrônica, informatização, robotização, modernização das plantas industriais -, a redefinição organizacional da empresa - novas técnicas de gestão -, o trabalho informal e o desemprego repercutem sobre os acidentes, as doenças do trabalho e os estilos de vida da população e evidenciam novas relações entre a política econômica e a saúde (Wünch Filho, 1995).

Essas transformações trazem à tona novas questões para os que atuam na área de saúde. O perfil epidemiológico dos trabalhadores caracteriza-se pela mistura de padrões heterogêneos de adoecimento e morte, em que os novos problemas de saúde-doença superpõem-se aos antigos e a morbidade dita ocupacional mescla-se com a nãoocupacional, resultando num tipo de mosaico. É cada vez mais difícil falar de um mundo do trabalho - que pertence à esfera da fábrica ou da produção - e de um mundo fora do trabalho, bem como definir com clareza quem são os trabalhadores (Dias, 2000).

No Brasil, na segunda metade do século XX, a população perdeu suas características rurais e adquiriu um perfil predominantemente urbano. Em 1950, pouco mais de 1/3 dos brasileiros vivia em domicílios urbanos, passando para mais da metade, em 1970, e para mais de 3/4, em 1991. O Censo Demográfico revelou que, em 2000, $81 \%$ dos brasileiros residiam nas cidades. Na Região Sudeste, o grau de urbanização chegou a $91 \%$ e, no Estado de São Paulo, a $93 \%$.

A mudança de um perfil essencialmente rural da sociedade brasileira para um predominantemente urbano tem origem na industrialização do país e no conseqüente desenvolvimento acelerado de pólos industriais, com a instalação da indústria automobilística, a partir da segunda metade da década de 50 e no transcorrer dos anos 60 . Na década de 70, intensificaram-se a instalação da indústria de bens de capital e os investimentos em infra-estrutura de transporte, comunicação e energia e foram implantadas as indústrias de alta tecnologia, como a bélica, a aeronáutica, a de informática e a nuclear. $\mathrm{O}$ ritmo do crescimento industrial e os investimentos deixaram de se expandir nos anos 80 , privilegiando projetos de modernização tecnológica e gerencial. Na década de 90 , a indústria nacional apresentou queda no volume produzido e o seu nível médio de produção industrial ficou praticamente igual ao dos anos 80 . O acréscimo pontual na produtividade aconteceu em virtude da automação e do aperfeiçoamento das técnicas de gerenciamento, predominantemente nos setores de ponta da indústria, em grande parte vinculados ao capital multinacional (Wünch Filho, 1995).

A População Economicamente Ativa - PEA, nos anos 70 e 80 , também sofreu profunda transformação: o setor primário retraiu-se, a classe operária urbana triplicou e o setor terciário tornou-se dominante. Em 1970, 44\% da PEA ocupada estava no setor primário, $18 \%$ no secundário e 38\% no terciário, enquanto em 1990 essa distribuição correspondia a $23 \%, 23 \%$ e $55 \%$, respectivamente. Em 2001, confirma-se tendência decrescente, com a participação de $21 \%$ do setor primário da economia.

As transformações das relações de trabalho no campo, mais intensas no Sudeste e no Centro-Oeste do que no Nordeste, incrementaram a produtividade com menor uso de mão-de-obra, quando as relações capitalistas de produção atingiram a atividade rural por meio da mecanização e do uso dos agrotóxicos.

O grupo de empregados com carteira assinada em atividade agrícola, entre 1999 e 2001, sofreu redução de, em média, 5,5\% ao ano, enquanto o de sem carteira de trabalho assinada registrou uma média anual de queda de $1,7 \%$. $\mathrm{O}$ crescimento do número de ocupados em atividades nãoagrícolas, (média de 3,8\% ao ano), ainda que importante, não foi suficiente para elevar o nível de ocupação total, havendo, nesses dois anos, crescente participação dos ocupados sem registro em carteira (uma média de 6,5\% ao ano).

A PEA feminina brasileira tem-se ampliado continuamente: 31\%, em 1980, 36\%, em 1991, e 44\%, em 2000. No Estado de São Paulo, a taxa de participação das mulheres no mercado de trabalho cresceu de $47 \%$ para $51 \%$, entre 1994 e 1998. Em geral, esse contingente em condições mais precárias que o de homens, pois grande parcela está inserida em empregos domésticos, em tarefas de apoio e de execução. Dados da Pesquisa de Emprego e Desemprego - PED, na Região Metropolitana de São Paulo, mostram que, entre 2000 e 2001 , houve redução de $6 \%$ no contingente de mulheres exercendo atividades de direção e planejamento. A mão-de-obra feminina continua recebendo rendimento inferior ao dos homens, mesmo quando desempenha função equivalente. Em 1998, as mulheres ocupadas recebiam, em média, $\mathrm{R} \$ 712$, valor $28 \%$ 
superior ao de 1994. Apesar do aumento, o rendimento médio feminino equivalia a $64 \%$ do masculino. As mulheres mantinham, em 1998, taxa de desemprego maior (20\%) que a dos homens (14\%). Além disso, as trabalhadoras ainda encontram-se expostas aos velhos e, principalmente, aos novos riscos ocupacionais, como as atividades repetitivas e a dupla jornada/carga de trabalho, o que acarreta maiores riscos para sua saúde.

As repercussões sociais advindas dessas transformações traduziram-se, desde os anos 60, nas migrações internas, nas alterações no processo de produção com a incorporação sistemática da tecnologia, na mudança das características do estilo de vida e nos perfis de saúde da população. $\mathrm{Na}$ perspectiva da saúde, os trabalhadores informais e os desempregados constituem população à margem das estatísticas de Saúde do Trabalhador. Não há registros dos acidentes e doenças do trabalho que atingem esse segmento, tornando obscura sua morbimortalidade ocupacional.

A OIT, na Reunião de Lima, em 1999, discutiu e se comprometeu com a necessidade de encontrar respostas contemporâneas ao marco teórico-prático da economia global e à demanda histórica, posta a nossas sociedades, que sejam capazes de gerar empregos de qualidade, que respeitem os direitos dos trabalhadores e desenvolvam formas modernas e efetivas de proteção social, habitação, alimentação, educação e ocupação adequada do tempo livre, tudo isso sintetizado na noção de trabalho decente.

A combinação das inovações tecnológicas com os novos métodos gerenciais gerou uma intensificação do trabalho, decorrente do aumento do ritmo, das responsabilidades e da complexidade das tarefas, que se traduziram numa série de agravos à saúde: envelhecimento prematuro, aumento do adoecimento e morte por doenças cardiovasculares e outras doenças crônico-degenerativas, especialmente as osteomusculares (Dort) relacionadas ao trabalho - conhecidas também como lesões por esforços repetitivos (LER) -, além de um conjunto de sintomas na esfera psíquica (Dias, 2000).

Os acidentes de trabalho, por outro lado, não estão mais associados apenas às atividades restritas ao ambiente das empresas/do local do trabalho, assim como os acidentes predominantes não correspondem mais àqueles relacionados diretamente com os processos intrínsecos ao trabalho. Os riscos mais gerais aos quais está submetida toda a população, principalmente as diversas formas de violência crescentes nas áreas urbanas, atingem de forma indiscriminada os trabalhadores que tiveram seu local de trabalho ampliado para o espaço público, acrescentando esses riscos àqueles inerentes aos processos produtivos (Waldvogel, 2002).

Do exposto, pode-se pensar que uma proposta de promoção de saúde do trabalhador tem que se fundamentar na complexidade de uma ordem sistêmica. Os fatores sistêmicos que envolvem os acidentes de trabalho compreendem múltiplas variáveis, tais como: técnicas de produção e de organização social do trabalho; dificuldades de adaptação cultural, como, por exemplo, do migrante quanto à mudança brusca de atividade e ao entendimento do novo espaço de trabalho, do percurso ou da moradia e das tecnologias desconhecidas; trânsito como gerador de acidentes; mudanças de ritmo na atividade desenvolvida e modificações na rotina - escala por turno/interrupções para treinamento/fadiga (horas extras/longa distância entre trabalho e residência/excesso de ruído); alimentação inadequada; falta de opção de lazer e de atividades para ocupação do tempo livre; poluição ambiental; violência urbana. Esse amplo conjunto de fatores deve levar a que se evite o senso comum de remeter ao trabalhador a culpa pelo acidente (Wünch Filho, 1995).

A agenda da OIT (1999), para a primeira década do século XXI, pode ser sintetizada por quatro objetivos/estratégias: promoção e aplicação dos princípios e direitos fundamentais no trabalho; promoção de políticas e programas destinados a gerar mais e melhores empregos; ampliação da cobertura e efetividade de proteção social para todos; e fortalecimento do tripartismo e do diálogo social.

Para se entender e intervir, portanto, sobre a saúde do trabalhador torna-se necessário combinar distintos enfoques, como a reestruturação produtiva na globalização da economia, as transformações urbanas, as mudanças organizacionais no trabalho, os fatores de risco industriais e ambientais e os aspectos da saúde psicofísica do trabalhador (Franco apud Dias, 2000). Nesse contexto, os riscos e os desafios a serem enfrentados pelos trabalhadores e suas representações - sindicatos, centrais e federações - e pela sociedade têm suscitado preocupação também entre produtores de estatísticas, pesquisadores, estudiosos e implementadores de políticas públicas, destacando-se, porém, que os problemas de saúde do trabalhador dificilmente poderão ser resolvidos por ações exclusivas do setor saúde.

A grandiosidade numérica dos potencialmente envolvidos na questão da promoção de saúde do trabalhador por si só justificaria investimentos em pesquisas e análises. Segundo o Censo de 2000, mais de 76 milhões de bra- 
sileiros, a partir dos dez anos de idade, constituíam a PEA ( $56 \%$ da população de dez anos e mais), que engloba assalariados com registro em carteira, autônomos, trabalhadores informais e desempregados procurando emprego.

Dias (2000) argumenta que é preciso compreender que os trabalhadores vivem, adoecem e morrem de forma compartilhada com a população de um determinado tempo, lugar e classe social, mas também de forma diferenciada, decorrente de sua inserção particular no processo produtivo, especificidade que deve ser contemplada em suas necessidades de saúde.

A compreensão dessas especificidades deve estar subjacente na elaboração de políticas e programas de saúde do trabalhador, desde o nível nacional até o local, observadas as novas bases de relação entre os entes federados, em que à União compete estabelecer as normas gerais, que podem ser suplementadas por Estados e municípios, no que couber, e a estes compete a execução de ações de prevenção, promoção e recuperação da saúde dos trabalhadores.

\section{A DESCENTRALIZAÇÃO DAS AÇÕES E DOS SERVIÇOS DE SAÚDE DO TRABALHADOR}

O Brasil vive um processo de descentralização de ações e serviços de saúde que já passou por vários estágios, desde os anos 80. A descentralização, de modo geral, pode ser definida como a transferência de poder do nível nacional para instâncias subnacionais e de competências para planejar, gerir, executar e tomar decisões. No âmbito das políticas públicas, este processo implica reestruturação no aparelho de Estado, que perpassa várias esferas de governo, envolvendo aspectos políticos, administrativos, técnicos e financeiros.

A transferência de recursos e de competências para as diferentes instâncias do sistema de saúde causa um impacto positivo na gestão e nas diversas modalidades de atenção, permitindo a geração e o desenho de novos modelos de atenção, papéis e funções, modalidades de capacitação, sistema de remuneração e novas formas de participação das instituições. A descentralização é condição necessária para melhorar o acesso, a participação, a qualidade, a sustentação e a eqüidade na saúde (Hortale et al. apud Dias, 2000).

A efetivação de transferências de ações e serviços para os municípios não está desonerada de dificuldades, muitas dessas originárias das próprias características dos municípios brasileiros. Para Mendes (1998), dado o modelo de federalismo brasileiro, no qual os municípios são entes federativos com autonomia política, administrativa e financeira e com competências constitucionais e infraconstitucionais bem estabelecidas, era natural que a descentralização do sistema de saúde reservasse, para eles, papel de protagonista. No entanto, o autor indica a complexidade que a questão assume quando se observam os altíssimos diferenciais de tamanho, população e desigualdades socioeconômicas entre os milhares de municípios brasileiros. Esses diferenciais, evidentemente, vão se refletir em distintos graus de competências administrativa e gerencial, bem como de capacidade instalada de serviços de saúde e de respostas às demandas de atenção à saúde da população.

No Brasil, o movimento pela descentralização começou a ganhar corpo em meados da década de 70, principalmente quando a oposição ao governo assumiu a administração de algumas prefeituras de médios e grandes municípios. Nos anos 80, foram implantadas duas estratégias que previam a transferência de ações de saúde para os municípios: o Programa de Ações Integradas de Saúde - AIS, em 1983, e o Sistema Unificado Descentralizado de Saúde - Suds, em 1987. Componente do ideário da Reforma Sanitária, a proposta de descentralização, com direção clara para a municipalização, vitalizou-se na década de 80, sendo inscrita na Constituição Federal de 1988.

As atribuições e competências de âmbito local foram dadas pela legislação infraconstitucional - as Leis Orgânicas da Saúde $n^{\circ} 8.080$ e 8.142/90 - e a aplicação dos preceitos estabelecidos foi e está sendo normatizada pelo Ministério da Saúde, por meio de diversas portarias, que dão a conformação da relação entre as três esferas de governo e, em particular, da gestão municipal.

O processo de descentralização orienta-se pelas Normas Operacionais Básicas (NOBs), editadas pelo Ministério da Saúde. A norma atualmente em vigor, a NOB/96, estabelece duas condições para os municípios em substituição às três que antecederam a Gestão Plena da Atenção Básica e a Gestão Plena do Sistema (Ministério da Saúde, 1996). As atribuições e responsabilidades definidas levam em conta a realidade do poder público, nos diversos municípios, caracterizada por diferentes modelos de organização, de diversificação de atividades, de disponibilidade de recursos e de capacitação técnicogerencial.

Os dados da Secretaria de Estado da Saúde indicam que $95 \%$ dos municípios de São Paulo, até outubro de 1999, haviam aderido aos novos modelos de gestão municipal de saúde, preconizados pela NOB/96, sendo que 
$71 \%$ optaram pela Gestão Plena da Atenção Básica e 24\% pela Gestão Plena do Sistema.

A Constituição Federal de 1988 é referência para a saúde do trabalhador e a partir dos seus preceitos, segundo Dias (2000), são elaborados os instrumentos legais e definidas as políticas de saúde e segurança no trabalho. As responsabilidades pela atenção à saúde do trabalhador são compartilhadas de forma diferenciada por empregadores, trabalhadores (através de suas representações) e Estado (no seu papel de mediador e condensador das forças sociais). Na esfera do Estado, atuam nessa questão os Ministérios do Trabalho, da Previdência Social, da Saúde e do Meio Ambiente, a Justiça do Trabalho e a Promotoria Pública. Dias (2000) elaborou, ainda, um apanhado das atribuições dos diferentes órgãos, descritos, de forma resumida, a seguir.

O Grupo Executivo Interinstitucional de Saúde do Trabalhador - Geisat, constituído por representantes dos Ministérios envolvidos com a questão, procura articular e racionalizar a atuação dos diferentes setores governamentais, evitar duplicação de ações e desperdício de recursos, compatibilizar e integrar as políticas e práticas de intervenção desenvolvidas pelo Estado.

A Constituição de 1988 atribuiu ao Ministério do Trabalho e Emprego a inspeção do trabalho em nível nacional, fundamentada nos dispositivos da Consolidação das Leis do Trabalho - CLT, nas Convenções Internacionais ratificadas pelo Brasil e nas cláusulas dos Contratos Coletivos de Trabalho. Conta com o apoio técnico da Fundacentro que, entre outras atividades, realiza estudos e pesquisas e desenvolve programas educacionais sobre diferentes assuntos que envolvem o trabalhador e respectivas condições do trabalho.

À Previdência Social cabe, por meio do Instituto Nacional do Seguro Social - INSS, a responsabilidade pelo pagamento dos benefícios, enquanto perdure a incapacidade decorrente de acidente do trabalho. Entre outras atribuições do INSS, estão os procedimentos de reabilitação profissional, de preparo e capacitação para acidentados ou incapacitados para a reinserção no mercado e a coleta, a consolidação e a divulgação de dados sobre ocorrência de acidentes de trabalho.

A Justiça do Trabalho integra o Poder Judiciário e congrega as Juntas de Conciliação e Julgamento, o Tribunal Regional do Trabalho e o Tribunal Superior do Trabalho.

O Ministério Público presta assistência jurídica às vítimas de acidentes e doenças do trabalho e/ou a seus dependentes, fiscaliza e acompanha denúncias de descumprimentos das Normas de Segurança e Medicina do
Trabalho, impetra ações de reparação de dano, interpreta e elabora pareceres técnicos que respaldem a atenção à saúde dos trabalhadores.

O Sistema Único de Saúde - SUS, alvo deste estudo, mantém Programas ou Centros de Referência à Saúde do Trabalhador, nos serviços próprios ou conveniados da rede pública.

Reppulo Jr. (2002) e Dias (2000) relatam que, antes mesmo de ser incluída na Constituição a atribuição ao SUS de executar ações de saúde do trabalhador, diversos programas municipais já haviam sido implantados, especialmente nos anos 80, com a criação de Programas e Centros de Referência em Saúde do Trabalhador, com influência do Modelo Operário Italiano e dos trabalhos da Medicina Social Latino-Americana, referências teórico-conceituais das ações de saúde do trabalhador nos serviços públicos.

O movimento da Reforma Sanitária desempenhou papel importante no resgate do poder de intervenção nos ambientes de trabalho pelo Ministério da Saúde, conforme apontam Vilela et al. (2001). Até 1988, as ações públicas em saúde do trabalhador eram centralizadas e se reduziam a inspeções tradicionais efetuadas por agentes do Ministério do Trabalho.

A Constituição estabelece que ao Sistema Único de Saúde compete, além de outras atribuições, executar as ações de vigilância sanitária e epidemiológica, bem como as de saúde do trabalhador (art. 200, II). A Lei Orgânica da Saúde regulamentou os preceitos constitucionais e definiu a participação do município na execução, controle e avaliação das ações referentes às condições e aos ambientes de trabalho, bem como a execução dos serviços de saúde do trabalhador. Neste dispositivo legal, entende-se por saúde do trabalhador o conjunto de atividades que se destinam, por intermédio de ações de vigilância epidemiológica e vigilância sanitária, à promoção, à proteção, à recuperação e à reabilitação da saúde dos trabalhadores que se submetem a riscos e agravos advindos das condições do trabalho, abrangendo:

- assistência ao trabalhador vítima do acidente do trabalho ou portador de doença profissional e do trabalho;

- participação, no âmbito da competência do SUS, em estudos, pesquisas, avaliação e controle dos riscos e agravos, potenciais à saúde, existentes no processo do trabalho;

- participação, no âmbito da competência do SUS, da normatização, fiscalização e controle das condições de produção, extração, armanezamento, transporte, distribuição e manuseio de substâncias, de produtos, de máquinas e de equipamentos que apresentam riscos à saúde do trabalhador; 
- avaliação do impacto que as tecnologias provocam à saúde;

- informação ao trabalhador e à sua respectiva entidade sindical e às empresas sobre os riscos de acidente do trabalho, doença profissional e do trabalho e sobre os resultados de fiscalizações, avaliações ambientais e exames de saúde, de admissão, periódicos e de demissão, respeitados os preceitos da ética profissional;

- participação na normatização, fiscalização e controle dos serviços de saúde do trabalhador nas instituições e empresas públicas e privadas;

- revisão periódica da listagem oficial de doenças originadas no processo de trabalho, tendo na sua elaboração a colaboração das entidades sindicais;

- garantia ao sindicato dos trabalhadores de requerer ao órgão competente a interdição de máquina, de setor de serviço ou de todo o ambiente de trabalho, quando houver exposição a risco iminente para a vida ou a saúde dos trabalhadores.

A instrumentalização dessas diretrizes consolidou-se pela Norma Operacional Básica de Saúde do Trabalhador - Nost/SUS, em 1998, que definiu as responsabilidades dos municípios em cada uma das duas condições de gestão (Plena de Atenção Básica e Plena do Sistema) definidas pela NOB 01/96. Os pressupostos básicos da Nost/SUS podem ser sintetizados em: universalidade das ações, independentemente de vínculos empregatícios formais no mercado de trabalho; integralidade das ações, compreendendo assistência, recuperação de agravos e prevenção por meio de intervenções nos processos de trabalho; direito à informação e controle social, com a incorporação dos trabalhadores e seus representantes, em todas as etapas da vigilância à saúde; e regionalização e hierarquização, através da execução das ações de saúde do trabalhador em todos os níveis da rede de serviços, organizados num sistema de referência e contra-referência, local e regional.

Vilela et al. (2001) destacam algumas atribuições que os municípios em processo de gestão plena devem assumir: ações de vigilância nos ambientes e processos de trabalho; aplicação de procedimentos administrativos e investigação epidemiológica; emissão de laudos sobre incapacidade do trabalhador seqüelado; implantação de serviços especializados de referência com a capacidade para estabelecimento de nexo causal dos agravos e para tratamento, recuperação e reabilitação do trabalhador; e instituição e manutenção de cadastro de empresas com a indicação dos fatores de risco.
O Estado de São Paulo aprimorou a legislação pertinente à saúde do trabalhador com edição de duas leis, na segunda metade dos anos 90. A Lei no 9.505/97 disciplina as ações e os serviços de saúde do trabalhador no SUS, constituindo-se em grande avanço nas definições legais das ações de assistência ao trabalhador e de vigilância dos ambientes de trabalho (Repullo Jr., 2002). O Código Sanitário de 1998 amplia as ações de vigilância à saúde sobre o meio ambiente, nele incluídas as atividades produtivas, e aprofunda a intervenção sobre as relações de trabalho, produtos e substâncias de interesse à saúde (Gouveia, 2000).

As ações de atenção à saúde do trabalhador devem ser organizadas para que seja prestada assistência multiprofissional às vítimas de doenças ocupacionais, de doenças relacionadas ao trabalho e de acidentes de trabalho, incluindo ações de diagnóstico, identificação de nexo causal, tratamento, recuperação e reabilitação, bem como a vigilância de ambientes de trabalho e prevenção de riscos. As ações de vigilância têm como objetivo identificar situações de riscos de acidentes e agravos a saúde e promover melhorias nas condições de segurança e saúde no trabalho, através de visitas às empresas e notificação sobre mudanças a serem realizadas. A assistência ao trabalhador vítima de acidente ou doenças do trabalho pode ser feita na rede básica ou em serviços especializados.

Repullo Jr. (2002) retrata duas correntes de organização dessas ações em seu estudo sobre cinco municípios paulistas. Em uma delas, as ações são implantadas de forma descentralizada na rede básica de saúde, cabendo aos médicos clínicos o atendimento aos trabalhadores. Esses clínicos contam com uma referência em Medicina do Trabalho num Centro de Especialidades para os atendimentos tecnologicamente mais complexos. A outra corrente preconiza a criação de Centros de Referência em Saúde do Trabalhador - CRST, que vêm sendo implantados no Brasil, principalmente em São Paul , desde o final dos anos 80. Ainda segundo o autor, co itraditoriamente, os CRSTs têm-se configurado como a porta de entrada do sistema, não se constituindo em se viços de referência secundária. Estes Centros, com equip s multiprofissionais especializadas, voltam-se única e exclusivamente para assistência, promoção de saúde do t abalhador e manejo previdenciário dos agravos.

Os princípios do SUS - planejam ento a partir do município, responsabilidade partilhada entre as três esferas de governo, envolvimento e particip ção da comunidade na definição das políticas públicas - êm como eixo e es- 
tratégia transformações sociais que garantam a saúde integral do cidadão e não apenas a prevenção e o combate a doenças. Acompanhar o contínuo processo de descentralização das ações e serviços de saúde é um estímulo à realização de pesquisas como a Pesquisa Municipal Unificada - PMU, da Fundação Seade, que contribui para a construção de banco de dados municipais e para a sistematização do uso da informação enquanto instrumento de gerenciamento e de direito de cidadania.

O processo da reestruturação produtiva em curso, com o crescimento do desemprego e da precarização do trabalho, aumenta as responsabilidades do SUS - única alternativa para cuidados com a saúde de expressivo contingente de trabalhadores - e traz ao sistema de saúde o desafio de compreender e lidar com a complexa situação em que as doenças profissionais entrelaçam-se às doenças comuns agravadas pelo trabalho (Dias, 2000).

Apesar das críticas dirigidas à atenção diferenciada e especializada, considerada verticalizada e de alcance restrito enquanto estratégia de atuação em saúde pública, a autora afirma, que a implementação dos Programas de Saúde do Trabalhador e dos Centros de Referência tem facilitado o desenvolvimento de ações que cumprem a prescrição legal de competência do SUS e que contribuem com a transformação das condições adoecedoras existentes no processo de trabalho.

Os programas e ações em favor da saúde do trabalhador devem ser entendidos, então, como um dos componentes da estratégia geral para o alcance da saúde para todos. A nova percepção do conceito de promoção de saúde do trabalhador transcende a perspectiva da prevenção dos acidentes de trabalho e das doenças profissionais e remete à necessidade de se conquistar a integralidade, favorecendo o desenvolvimento de diferentes estilos de vida em comunidades saudáveis (Ministério da Saúde, 1999).

Este trabalho procura dar visibilidade às ações de saúde do trabalhador, atendo-se ao estudo do assunto sob a ótica da política pública municipal, por meio de análise dos dados e informações da PMU, realizada pela Fundação Seade, em todos os municípios paulistas, em 1995, 1997 e 1999.

\section{ANÁLISE DOS RESULTADOS DA PESQUISA MUNICIPAL UNIFICADA}

A PMU é um dos projetos tradicionais da Fundação SEADE, que investiga a capacidade organizacional, administrativa e financeira das prefeituras, além da realida- de socioeconômica, cultural e urbana municipal, permitindo acesso a uma radiografia dos 645 municípios do Estado de São Paulo. Trata-se de uma das únicas pesquisas em que as prefeituras municipais são fontes primárias de dados, cobrindo o universo dos municípios e um extenso rol de aspectos da administração pública, com acompanhamento bianual.

Dos aspectos abordados no tema Saúde - política e organização administrativa, recursos humanos, programas e ações de saúde -, selecionaram-se, para este estudo, as variáveis que possibilitam conhecer, em âmbito municipal, a atuação do SUS, no que a ele compete, sobre a saúde do trabalhador e elaborar uma análise de suas ações, em 1995, 1997 e 1999.

A PMU permite identificar as ações das prefeituras no que se refere a vistoria e fiscalização de ambientes de trabalho, intervenção preventiva em ambientes com riscos de acidentes ou doenças profissionais, oferta de atendimento especializado em saúde do trabalhador, oferta de serviços de reabilitação física aos acidentados de trabalho e realização de campanhas e/ou ações educativas de prevenção aos riscos de acidentes e doenças do trabalho.

A pesquisa, nas três aplicações referidas, identificou um conjunto de ações que, não necessariamente, foram feitas de forma programática, ou seja, como resultado da execução de um Progama de Saúde do Trabalhador. Diante da heterogeneidade do conjunto dos 645 municípios paulistas, a configuração dos sistemas municipais de saúde também deve ser marcada por uma diferenciação na capacidade e na disponibilidade política das prefeituras e das comunidades em assumirem novas atribuições. Nesse texto procurou-se identificar aspectos que diferenciem essas políticas e atuação.

A criação de 20 novos municípios no Estado de São Paulo, entre 1995 e 1997, e a falta de informações em algum dos três anos analisados, devido à recusa de parcela das prefeituras em responder à pesquisa ou por inconsistências verificadas nas respostas, levaram à elaboração de um painel fixo de 520 municípios, entre os 645 do Estado, o que permite a comparação entre os anos pesquisados e a análise da evolução do fenômeno investigado.

Tendo em vista as diversidades locais - porte populacional e dinâmica econômica, social e urbana -, os municípios foram classificados em três estratos populacionais: até 50 mil habitantes; entre 50 e 200 mil; e acima de 200 mil habitantes. ${ }^{1}$

Além da classificação por estrato populacional, os municípios foram analisados segundo sua adesão às con- 
dições de gestão municipal da saúde: Gestão Plena da Atenção Básica e Gestão Plena do Sistema de Saúde, que estipulam diferentes graus de responsabilidade e atribuições na área de saúde.

Os resultados apontam que, em 1999, pouco mais de $1 / 4$ dos municípios paulistas desenvolvia ações de saúde do trabalhador. Essa proporção diminuiu no período analisado, independentemente do porte populacional, passando de $30,2 \%$, em 1995 , para $26,5 \%$, em 1997 , e $26,2 \%$ em 1999. Ressalve-se que, no grupo dos municípios com mais de 200 mil habitantes, houve uma retomada do crescimento entre 1997 e 1999, que pode ser atribuída às normas implantadas no período - a NOB/96 e a Nost/98.

O levantamento revelou, também, que o tamanho da população é uma variável que interfere diretamente na realização, ou não, de ações de saúde do trabalhador pelas prefeituras. Enquanto, em 1999, apenas 21,4\% dos municípios com até 50 mil habitantes, desenvolveram esse tipo de ações, no grupo daqueles com mais de 200 mil habitantes esse percentual correspondeu a $63,6 \%$ (Tabela 1).

Uma hipótese para esse fenômeno é a de que as cidades maiores, mais ricas no que se refere à arrecadação de impostos e à participação nas transferências constitucionais de recursos financeiros, também possuem sociedades mais complexas em termos de estrutura produtiva, ambiente favorável e potencialmente gerador de eventos que exigem a existência e a manutenção de sistemas de proteção à saúde de seus trabalhadores. São também cidades com tradição em tratar da questão, uma vez que nelas foi implantada a maioria dos Centros de Referência de Saúde do Trabalhador, na década de 80 .

Se a abordagem, porém, privilegiar a realização dessas ações, de acordo com a condição de gestão do município, verifica-se que houve redução na oferta desses serviços em

TABELA 1

Municípios que Realizaram Ações de Saúde do Trabalhador, segundo Estratos Populacionais

Estado de São Paulo - 1995-1999

\begin{tabular}{lccc}
\hline Estratos Populacionais & 1995 & 1997 & 1999 \\
\hline Total & 30,2 & 26,5 & 26,2 \\
Até 50.000 Habitantes & 25,3 & 22,4 & 21,4 \\
De 50.001 a 200.000 Habitantes & 43,0 & 41,8 & 40,5 \\
Acima de 200.000 Habitantes & 77,3 & 54,5 & 63,6
\end{tabular}

Fonte: Fundação Seade. Pesquisa Municipal Unificada - PMU.

Nota: Refere-se aos 520 municípios que responderam a PMU nos três períodos considerados. municípios que aderiram à gestão Plena da Atenção Básica (de 28,3\%, em 1995, para 20,1\%, em 1999), enquanto, em sentido oposto, a oferta cresceu naqueles em gestão Plena do Sistema (de 35,2\% para 42,1\%, respectivamente).

Essa informação não constitui exatamente uma surpresa, pois esperava-se que os municípios, nesse segundo modelo de gestão, tivessem maior capacidade instalada e oferecessem um rol mais amplo de ações e serviços em favor da saúde de suas populações. Além disso, essas cidades possuem maior autonomia na gestão do sistema local e recebem aportes de recursos mais significativos do Ministério da Saúde, inclusive para realizar pagamentos pela prestação de serviços realizados por prestadores privados e filantrópicos.

A análise dos dados revela, também, que a ação de saúde do trabalhador mais comum nos municípios paulistas, em 1995, foi a de vistoria e fiscalização de ambientes de trabalho $(54,1 \%)$, enquanto a menos desenvolvida refere-se à oferta de serviços de atendimento especializado em saúde do trabalhador (31,2\%). Verificou-se a mesma situação em 1999, provavelmente porque a segunda ação requer a existência de um serviço com instalações específicas e profissionais especializados para esse fim, o que exige recursos e estrutura dos municípios para implementá-la.

Tanto nos municípios com até 50 mil habitantes quanto naqueles entre 50 e 200 mil, a ação mais comum foi vistoria e fiscalização de ambientes de trabalho $(64,4 \%$ e $59,4 \%$, respectivamente), conforme indica a Tabela 4 . Esse tipo de ação permite a identificação de riscos potenciais à saúde do trabalhador - decorrentes de agentes físicos, químicos ou biológicos, que podem levar a acidentes e doenças - e a conseqüente notificação às empresas para que procedam as modificações necessárias nos processos e/ou nos ambientes de trabalho.

TABELA 2

Municípios que Realizaram Ações de Saúde do Trabalhador, segundo Condições de Gestão (1) Estado de São Paulo - 1995-1999

\begin{tabular}{lccc} 
& & & Em porcentagem \\
\hline Condições de Gestão (1) & 1995 & 1997 & 1999 \\
\hline Total & 30,2 & 26,5 & 26,2 \\
Gestão Plena de Atenção Básica & 28,3 & 21,4 & 20,1 \\
Gestão Plena do Sistema & 35,2 & 40,0 & 42,1
\end{tabular}

Fonte: Fundação Seade. Pesquisa Municipal Unificada - PMU.

(1) Estabelecida pela Norma Operacional do Ministério da Saúde NOB-SUS 1996.

Nota: Refere-se aos 520 municípios que responderam a PMU nos três períodos considerados. 
Também foram mencionadas com freqüência, nesses municípios, a oferta de serviços de reabilitação física aos acidentados de trabalho ( $60 \%$ e $53,1 \%$, respectivamente) e a intervenção preventiva em ambientes com riscos de acidentes e doenças profissionais (48,9\% e 53,1\%).

É possível afirmar que o conjunto dos municípios com até 200 mil habitantes organizou suas ações de saúde do trabalhador de maneira semelhante, priorizando a prevenção (vistoria em ambientes de trabalho e intervenção naqueles que apresentam riscos de agravo à saúde do trabalhador) e a reabilitação física de acidentados do trabalho. Menos freqüente foi a oferta de serviços de atendimento especializado em saúde do trabalhador (apenas 31,1\% dos municípios com menos de 50 mil habitantes e metade daqueles entre 50 e 200 mil habitantes). É provável que os atendimentos de questões específicas do trabalhador se-

\section{TABELA 3}

Municípios que Realizaram Ações de Saúde do Trabalhador, segundo Tipos de Ação

Estado de São Paulo - 1995-1999

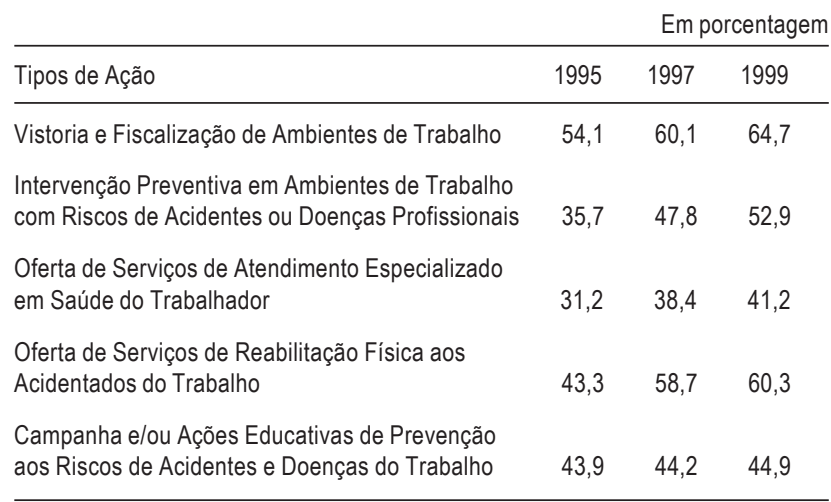

Fonte: Fundação Seade. Pesquisa Municipal Unificada - PMU.

Nota: Percentuais calculados sobre os municipios que afirmaram realizar ações de saúde do trabalhador em cada ano considerado: 157 municipios em 1995; 138 municipios em 1997; e

136 municipios em 1999. jam realizados na rede básica, sendo os casos mais complexos referenciados para outros municípios.

Quanto às cidades com população superior a 200 mil habitantes, a ação mais citada refere-se a campanhas e/ou ações educativas de prevenção aos riscos de acidentes de trabalho (92,9\%). Curiosamente, essa ação não foi referida com a mesma freqüência em cidades menores, talvez porque a estratégia de promoção da saúde tradicionalmente seja mais comum em grandes cidades, com sistemas mais complexos e maiores riscos de agravos. As campanhas educativas são determinantes para a proteção do trabalhador e para a redução de acidentes, doenças, invalidez e mortes.

A totalidade das ações investigadas foi referenciada por, pelo menos, 78,6\% dos municípios com mais de $200 \mathrm{mil}$ habitantes, evidenciando que, na organização do sistema de saúde dos maiores municípios, pelas suas características, foi possível estruturar de maneira mais adequada esse tipo de ações e serviços.

Numa análise final, o cruzamento entre a condição de gestão e as ações desenvolvidas revelou que, independentemente do tipo de atividade que realizam, os municípios em gestão Plena do Sistema oferecem com maior freqüência ações de saúde do trabalhador do que aqueles em gestão Plena da Atenção Básica, especialmente quando se trata da oferta de serviços especializados. Nota-se que, na organização dos sistemas locais, $55,7 \%$ das cidades do primeiro grupo possuíam serviço de atendimento especializado em saúde do trabalhador, fenômeno registrado apenas em 29,3\% daqueles do segundo grupo. Pode-se supor, então, que a atenção à saúde do trabalhador, nos municípios em gestão básica, ocorre sem que, necessariamente, possuam um serviço especializado para esse fim, sendo o atendimento realizado na rede de atenção básica ou, nos casos mais graves, referenciados para serviços em outros municípios.

TABELA 4

Municípios que Realizaram Ações de Saúde do Trabalhador, por Estrato Populacional, segundo Tipos de Ação Estado de São Paulo - 1999

\begin{tabular}{lccc} 
& & Em porcentagem \\
\hline Tipos de Ação & $\begin{array}{c}\text { Até } 50.000 \\
\text { Habitantes }\end{array}$ & $\begin{array}{c}\text { De 50.001 a 200.000 } \\
\text { Habitantes }\end{array}$ & $\begin{array}{c}\text { Acima de 200.000 } \\
\text { Habitantes }\end{array}$ \\
\hline Vistoria e Fiscalização de Ambientes de Trabalho & 64,4 & 59,4 & 78,6 \\
Intervenção Preventiva em Ambientes de Trabalho com Riscos de Acidentes ou Doenças Profissionais & 48,9 & 53,1 & 78,6 \\
Oferta de Serviços de Atendimento Especializado em Saúde do Trabalhador & 31,1 & 50,0 & 85,7 \\
Oferta de Serviços de Reabilitação Física aos Acidentados do Trabalho & 60,0 & 53,1 & 78,6 \\
Campanha e/ou Ações Educativas de Prevenção aos Riscos de Acidentes e Doenças do Trabalho & 41,1 & 34,4 & 92,9
\end{tabular}

Fonte: Fundação Seade. Pesquisa Municipal Unificada - PMU.

Nota: Percentuais calculados sobre os municipios que afirmaram realizar ações de saúde do trabalhador em cada estrato considerado: 90 municipios com até 50.000 habitantes; 32 municípios entre 50.001 e 200.000 habitantes; e 14 municipios acima de 200.000 habitantes. 


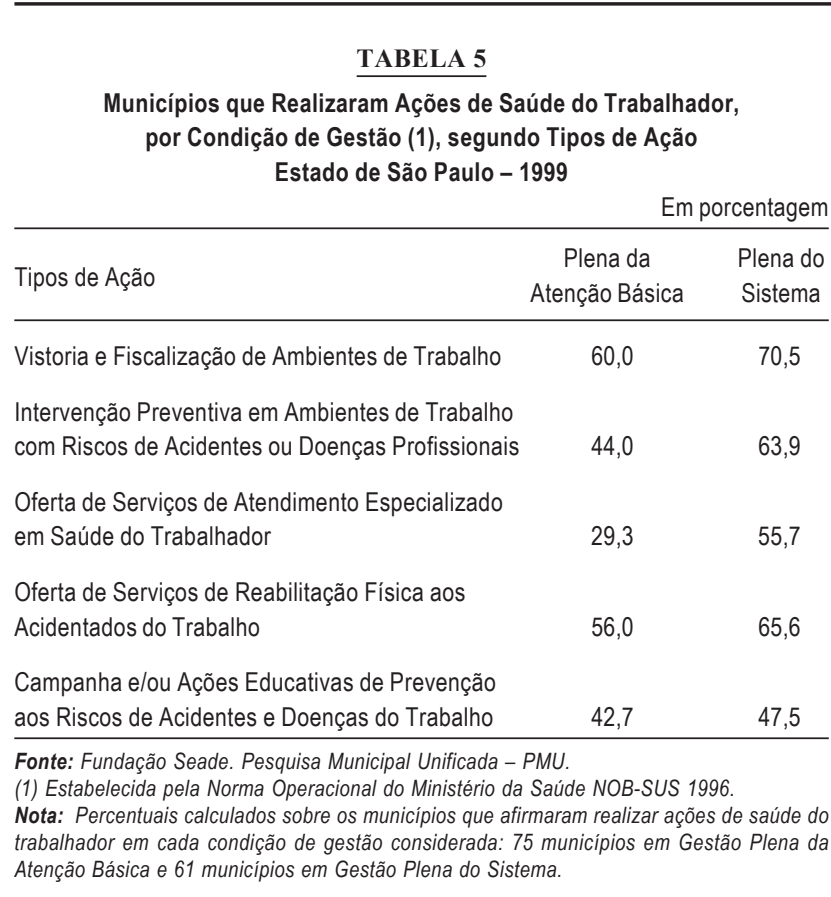

Tanto nos municípios em gestão Plena do Sistema como naqueles em gestão Plena da Atenção Básica, as ações mais comuns foram a vistoria e fiscalização de ambientes de trabalho (70,5\% e $60 \%$, respectivamente) e a oferta de serviços de reabilitação física aos acidentados de trabalho $(65,6 \%$ e $56 \%)$, que, em diversas cidades do Estado, especialmente nas pequenas e médias, consiste em serviço de fisioterapia realizado em ambulatórios de especialidades, unidades mistas ou mesmo em centros de saúde.

\section{CONSIDERAÇÕES FINAIS}

O SUS constitui um espaço público privilegiado que dispõe de atendimento universalizado (atinge o maior número de trabalhadores possível, com ou sem carteira assinada), recursos físicos, humanos, tecnologia e técnicas acumuladas e, portanto, é uma conquista social capaz de construir uma prática diferenciada sim, porém, inovadora e transformadora, sustentada no novo perfil epidemiológico da força de trabalho e no referencial da Promoção da Saúde.

A saúde do trabalhador envolve um marco teórico-prático complexo que não pode ser visualizado por um único viés. Seu conhecimento e compreensão exigem visão ampla e profunda do contexto histórico ao qual a sociedade do trabalho está inserida e dos nexos causais trabalho/saúde/doença.
Nesse cenário adquirem centralidade a implementação da produção de estatísticas, os indicadores e análises de informações sobre acidentes de trabalho, doenças profissionais e doenças relacionadas ao trabalho, a implantação e implementação de serviços que compreendam equipes multiprofissionais para execução de ações de diagnóstico e tratamento, as ações intersetoriais de promoção e proteção à saúde, de sensibilização e capacitação de recursos humanos, o desenvolvimento de parcerias e ações conjuntas entre entidades de trabalhadores e organizações governamentais e não-governamentais que investigam o assunto (Universidades, Fundações, Centros de Estudos, entre outras) e as realizações de eventos/campanhas educativos (seminários, debates, conferências e congêneres) para trabalhadores em geral, cipeiros, empregadores, sindicatos, centrais sindicais, gestores de políticas públicas e interessados.

Embora se reconheça como legítima a necessidade, apontada pelos estudiosos, de uma mudança de eixo nas ações de saúde do trabalhador - que transcendam a simples assistência ao dano do acidentado, à doença profissional e/ou àquela relacionada ao trabalho para a busca da integração dos enfoques saúde, segurança dos trabalhadores e meio ambiente -, o objetivo da PMU, no período investigado, foi o de caracterizar o panorama geral da implantação da descentralização, no caso das ações essenciais de atendimento aos agravos decorrentes do mundo do trabalho (acidentes e doenças) e respectivas ações de vigilância (fiscalização, controle e intervenção) e de prevenção (campanhas e ações educativas), previstas em lei. Isto se reveste de importância diante do processo recente que tem gerado experiências diversas e multiformes, de acordo com as realidades locais e regionais. A complexidade da questão coloca uma série de novas demandas de investigação, como o acompanhamento da implantação das novas diretrizes estabelecidas em particular pela Nost, a estruturação e a capacitação de equipes e o financiamento dessas ações.

\section{NOTA}

1. Exclui o Município de São Paulo que não respondeu à PMU 1995.

\section{REFERÊNCIAS BIBLIOGRÁFICAS}

DIAS, E.C. A organização da atenção à saúde do trabalhador. In: FERREIRA FILHO, M. (Org.). Saúde no trabalho. São Paulo: Rocca, 2000. 
FUNDAÇÃO INSTITUTO BRASILEIRO DE GEOGRAFIA E ESTATÍSTICA - IBGE. Censo Demográfico 2000. Disponível em: $<$ http://www.ibge.gov.br/censo2000/default.shtm>. Acesso em: 14 out. 2002.

. Pesquisa Nacional por Amostra de Domicílios - PNAD - Sintese de Indicadores 2001. Rio de Janeiro: IBGE, 2002.

FUNDAÇÃO SEADE. O mercado de trabalho feminino na Região Metropolitana de São Paulo em 2001. Boletim Mulher e Trabalho, São Paulo, n.7, mar. 2002.

. O mercado de trabalho feminino no Estado de São Paulo - 1994-98. Boletim Mulher e Trabalho, São Paulo, n.1, jul. 2000.

GOUVEIA, R. Saúde pública, suprema lei; a nova legislação para a conquista da saúde. São Paulo: Mandacaru, 2000.

MENDES, E.V. (Org.). A organização da saúde no nível local. São Paulo: Hucitec, 1998.

MINISTÉRIO DA SAÚDE. Projeto promoção da saúde. Disponível em: $<$ http://www.saude.gov.br/sps/areastecnicas/promocao/ home.htm>. Acesso em: 26 set. 2002.

OIT/LIMA: XIV Reunião Regional dos Estados Americanos... Prólogo. PRIORIDADES DA OIT NAS AMÉRICAS. Conclusões. Disponível em:

$<$ itamericas99.org.pe/spanish/conclus/text por.shtml $>$. Acesso em: 06 ago. 2002.
REPULLO Jr., R. A municipalização das ações de saúde do trabalhador no Sistema Único de Saúde. 2002. Tese (Doutorado) - Faculdade de Saúde Pública da Universidade de São Paulo, São Paulo, 2002.

VILELA, R.A. et al. Experiência do programa de saúde do trabalhador de Piracicaba: desafios da vigilância de acidentes. Informe epidemiológico do SUS 2001, 10(2), p.81-92, abr.-maio- jun. 2002.

WALDVOGEL, B.C. Acidentes de trabalho: os casos fatais, a questão da identificação e da mensuração. Belo Horizonte: Fundacentro, 2002.

WÜNCH FILHO, V. Variações e tendências na morbimortalidade dos trabalhadores. In: MONTEIRO, C.A. (Org.). Velhos e novos males da saúde no Brasil: a evolução do país e suas doenças. São Paulo: Hucitec/Nupens/USP, 1995.

Zilda Pereira da Silva: Socióloga, Analista da Fundação SEADE.

Irineu Francisco Barreto Junior: Sociólogo, Analista da Fundação SEADE.

Maria do Carmo Sant'Ana: Historiadora, especialista em Promoção de Saúde pela Faculdade de Saúde Pública da USP, Analista da Fundação SEADE. 